\title{
EVALUASI IMPLEMENTASI MANAJEMEN RUMAH SAKIT DALAM RANGKA GREEN HOSPITAL DI WILAYAH BALI
}

\author{
Brando Harison Sigalingging \\ Manajemen Lingkungan, Pascasarjana Universitas Negeri Jakarta, email: \\ brandoharisonsigalingging@gmail.com
}

\begin{abstract}
Abstrak
Jumlah rumah sakit yang semakin bertambah banyak berpengaruh terhadap kerusakan lingkungan apabil tidak dikelola dengan baik. Kerusakan lingkungan menjadi tanggungjawab bersama-sama baik dari pihak pemerintah, swasta dan masyarakat. Di indonesia saat ini bahkan belum ada rumah sakit yang sudah termasuk green hospital, namun pemerintah mempersiapkan pada tahun 2020 setiap rumah sakit diharapkan dapat berpartisipasi dalam mengelola secara baik dengan selalu mempertimbangkan aspek kesehatan, ekonomi, ekologi dan sosial sehingga prinsip pemenuhan konsep pembangunan berkelanjutan dalam bidang kesehatan akan terpenuhi, dan rumah sakit dapat ikut berperan aktif dalam meminimalisasi dampak perubahan iklim. Penelitian ini menggunakan teknik analisis secara deskriptif .Dari hasil penelitian ini menyatakan bahwa dari 10 kategori green hopsital dunia rumah sakit di Bali masih harus banyak yang di persiapkan.
\end{abstract}

Kata kunci : Kajian Teoritik, Green Hospital, Bali

\begin{abstract}
The increasing number of hospitals has an effect on the environmental damage of apabil not well managed. Environmental damage is a shared responsibility of both the government, the private sector and the public. In Indonesia today there is not even a hospital that already includes a green hospital, but the government prepares by 2020 every hospital is expected to participate in managing well by always considering the health, economic, ecological and social aspects so that the principle of fulfillment of the concept of sustainable development in the field health will be met, and hospitals can play an active role in minimizing the impacts of climate change. This research uses descriptive analysis techniques. From the results of this study states that of the 10 categories of world green hopsital hospitals in Bali still have much to prepare.
\end{abstract}

Key Words : Theoretical Studies, Green Hospital, Bali 


\section{PENDAHULUAN}

Jumlah rumah sakit di Indonesia semakin meningkat membuat keberadaan tiap-tiap rumah sakit dalam satu kesatuan ekosistem ditengah isu dampak perubahan iklim dan pemanasan global serta degradasi lingkungan dipandang perlu bertanggung jawab atas pembangunan keberlanjutan demi menjaga kualitas lingkungan dan pemanfaatan sumber daya alam. Menurut pasal 33 UUD 1945 ayat 4 mengatakan perekonomian nasional diselenggarakan berdasar atas demokrasi ekonomi dengan prinsip kebersamaan, efisiensi berkeadilan, berkelanjutan, berwawasan lingkungan, kemandirian, serta dengan menjaga keseimbangan kemajuan dan kesatuan ekonomi nasional.

Berbagai upaya dilakukan agar rumah sakit bisa mengakomodasi pemanfaatan potensi alam secara efektif dan efisien. Sumber daya rumah sakit berbasis alam dan lingkungan hidup seperti air bersih, energi, kertas dan material lainnya yang merupakan kebutuhan harian pengoperasian rumah sakit yang penggunaannya juga perlu dilandasi oleh prinsip eco-efficiency, sementara produk yang dihasilkan rumah sakit seperti limbah cair, padat dan gas perlu diolah sehingga targetnya tidak saja untuk memenuhi baku mutu limbah, juga untuk memenuhi kaidah reduce, reuse, recycle dan recovery.
Pada prinsipnya, model rumah sakit dimasa mendatang perlu dikelola secara baik dengan selalu mempertimbangkan aspek kesehatan, ekonomi, ekologi dan sosial sehingga prinsip pemenuhan konsep pembangunan berkelanjutan dalam bidang kesehatan akan terpenuhi, dan rumah sakit dapat ikut berperan aktif dalam meminimalisasi dampak perubahan iklim serta, bagaimana kebijakan Organisasi Kesehatan Dunia (WHO) dalam Healthy Hospitals, healthy planet, healthy people (Addressing Climate Change in Health Care Settings).

Rumah sakit merupakan salah satu dari hasil pembangunan karena rumah sakit yang dibangun merupakan sarana pelayanan umum bagi masyarakat. Menurut (Muninjaya : 2005) Rumah sakit merupakan bagian dari sistem pelayanan publik kesehatan yang harus memenuhi kriteria availability, appropriateness, continuity sustainability, acceptability, affordable, dan quality. Keberadaan rumah sakit sangat dibutuhkan oleh masyarakat mengingat bahwa fungsi dari rumah sakit itu adalah sebagai penyembuh penyakit dan pencegahan penyakit.

Menurut dr Supriyanto Sp.S MARS selaku Direktur Jendral Bina Upaya Kesehatan, pada tahun 2020 rumah sakit di Indonesia harus menerapkan green 
hospital. Berdasarkan intruksi Menteri

Dalam Negeri No. 14 Tahun 1988 mengemukakan bahwa Green Hospital memberikan manfaat yaitu kesegaran, kenyamanan, keindahan dan lingkungan yang bersih dan sehat. Untuk mewujudkan rumah sakit yang ramah lingkungan ada kriteria yang perlu dipenuhi oleh rumah sakit. Namun belum ada standar kriteria yang berlaku diseluruh dunia. Penerapan green hospital didasarkan pada kondisi masing-masing negara dihubungkan dengan kebutuhan lokal serta aksi lingkungan dan praktek pencegahan primer yang secara aktif terlibat dalam upaya untuk meningkatkan kesehatan lingkungan masyarakat, kesetaraan kesehatan, dan ekonomi hijau (Balifokus :2010)

Health Care Without Harm menyebutkan ada 10 kriteria green hospital diantaranya adalah, kepemimpinan yang memprioritaskan kesehatan lingkungan, penggunaan bahan kimia dan obat-obatan, pengelolaan limbah, efiseinsi energi dan air, penyediaan makanan yang sehat, konstruksi bangunan dan pengadaan barang.

Untuk membantu mewujudkan rumah sakit yang ramah lingkungan diperlukan seorang pemimpin yang memprioritaskan kesehatan lingkungan dalam mengatasi permasalahan dan pengelolaan lingkungan. Pemimpin menurut (Stephen. P. Robbins 2005) adalah orang yang mampu mempengaruhi orang lain dan memiliki wewenang manajerial, sedangkan kepemimpinan lingkungan merupakan kemampuan untuk mempengaruhi individu dan memobilisasi organisasi untuk mewujudkan visi keberlanjutan ekologis jangka panjang (Egri dan Herman 2000).

Dalam kegiatan yang ada dirumah sakit setiap hari menghasilkan limbah, baik dalam bentuk padat, cair dan gas yang terbagi dalam limbah medis dan non medis. Negara berkembang menghasilkan 0,8 sampai $6 \mathrm{~kg}$ per orang per tahun (Chandra :2011). Rumah Sakit Kuwait mengahasilkan sampah per hari bervariasi antara 3,87 kg/tempat tidur/hari sampai 7,44 kg/tempat tidur/hari. Sampah tersebut terdiri dari sampah non medis sebesar $71,44 \%$ dan limbah infeksius sebesar 27,8 $\%$ dan $0,76 \%$ limbah benda tajam (Alhumoud, J.M : 2011).

Survey di Rumah Sakit Yordania mengatakan, rata-rata sampah yang dihasilkan berkisar antara 0,29 sampai 1,36 $\mathrm{kg} /$ tempat tidur/hari dengan total sampah harian sebesar 6 ton/hari. Berdasarkan survey, rumah sakit pemerintah menghasilkan $25 \%$ limbah infeksius, rumah sakit swasta sebesar $16 \%$ dan rumah sakit pendidikan sebesar 16\% (Shabib MN :2006). Hasil kajian terhadap rumah sakit yang ada di Bandung pada tahun 2010 menunjukkan jumlah sampah rumah sakit yang dihasilkan di Bandung sebesar 3.493 
ton per tahun. Komposisi sampah rumah sakit terdiri atas $85 \%$ limbah domestic, $15 \%$ limbah medis, terdiri atas $11 \%$ limbah infeksius dan $4 \%$ limbah berbahaya, dan limbah domestik yang sudah dimanfaatkan hanya sebesar 19\% (Chandra,B. :2007).

Dari data tersebut perlu dilakukan pengelolaan limbah Rumah sakit yang efektif dan efisien. Dibutuhkan seorang pemimpin yang mampu mengelola, karena berbagai jenis limbah medis dan non medis di rumah sakit perlu dilakukan manajemen. Menerapkan kebijakan mengenai pengelolaan limbah layanan kesehatan, fasilitas medis dan lembaga penelitian semakin dekat dalam memenuhi tujuan mewujudkan lingkungan yang sehat dan aman bagi karyawan mereka maupun bagi masyarakat sekitar ( A. Pruss :2005). Penelitian (Yahar : 2011) mengatakan masih banyak permasalahan yang terjadi dalam hal pengelolaan limbah di RSUD kab. Baru mulai dari pemilahan, pewadahan, pengangkutan hingga TPS tidak sesuai dengan permenkes no 1204/MENKES/X/2004.

Penghematan energi, air dan penggunaan bahan kimia dan obat-obat serta pemenuhan kebutuhan makanan yan sehat, kontruksi bangunan yang baik dan pengadaan barang rumah sakit yang ramah lingkunga merupakan hal yang baik untuk dilakukan. Pada penelitian dirumah sakit Surya Husada Denpasar menunjukkan
DOI : doi.org/10.21009/jgg.082.03

rancangan manajemen energi yang disusun mengacu pada matriks manajemen energi. Hasil matriks manajemen energi menunjukan bahwa manajemen energi rumah sakit belum terkelola dengan baik namun dalam hal penerapan teknologi dan sistem perawatan lampu dan AC dapat dijadikan best practice (I Putu Gede, Rukmi Sari 2012). Presentasi penggunaan energi listrik di RSAL dr. Ramelan Surabaya yaitu energi listrik 46,5\%, BBM 32,5\%, Air 12,95\% dan LPG 6,8\%. Audit sebelumnya mengatakan Intensitas Konsumsi Energi (IKE) rata-rata 9,44 $\mathrm{kWh} / \mathrm{m} 2$ perbulan, namun etika dilakukan audit setelah melakukan penghematan, Intensitas Kosumsi Energi (IKE)a menjadi 7,7 $\mathrm{kWh} / \mathrm{m} 2$ dalam sebulan (Resti Permata,Sarwono). Hasil penelitian (Fahriza Risnawati, P.Purwanto, 2015) beberapa alternatif perbaikan yang dapat dilakukan berkaitan dengan eko-efisiensi dalam manajemen lingkun- gan di RSPC dengan menggunakan konsep green hospital dari yang paling mudah diterapkan karena mendapat total nilai indikator tertinggi yaitu peningkatan setting temperatur pada penggunaan $\mathrm{AC}$ (8 poin), lalu pembuatan lubang biopori sebagai upaya pemanfaatan sampah organik menjadi pupuk kompos (6 poin), dan yang paling sulit untuk diterapkan adalah penggunaan kembali sisa air hasil Reverse Osmosis dari instalasi laboratorium (5 poin). Upaya-upaya 
tersebut dapat memberikan manfaat berupa peningkatan valuasi ekonomi dan lingkungan di Rumah Sakit Pertamina Cirebon.

Berdasarkan penelitian menyatakan Pengelolaan limbah non medis dalam hal wadah limbah, dan pengumpulan dan pengangkutan limbah memberi efek langsung pada kenyamanan dan kepuasan pasien. Meski pengelolaan limbah non medis tidak memberi efek langsung pada kepuasan pasien, namun kenyamanan pasien menunjukkan bahwa pasien merasa puas dengan lingkungan yang dibangun. Dengan demikian, kenyamaan pasien memberi efek pada kepuasan pasien. Indikator kenyamanan pasien adalah udara segar, suhu, dan kelembaban rumah sakit.

Berdasarkan penelitian terdahulu menyatakan Pengelolaan limbah rumah sakit dapat dilakukan dengan berbagai cara, yang diutamakan adalah sterilisasi, yakni berupa pengurangan dalam hal jumlah, penggunaan kembali dengan sterilisasi terlebih dahulu, daur ulang dan pengelolaan. Hal-hal yang perlu dipertimbangkan dalam pengelolaan limbah adalah pemisahan limbah, peyimpanan, penanganan limbah dan pembuangan limbah.

Di sebuah rumah sakit harus dilakukan penanganan atau pengelolaan, peyimpanan dan juga pengangkutan limbah medis dengan baik dan sesuai aturan pengolahan ramah lingkungan agar tidak menimbulkan
DOI : doi.org/10.21009/jgg.082.03

masalah kesehatan. Dikelola dengan baiknya limbah medis dan non medis rumah sakit diharapkan membawa dampak yang sangat penting yaitu menuju green hospital.

Sesuai dengan keputusan MenKes R.I No. 1204/MENKES/SK/X/2004 tentang persyaratan kesehatan lingkungan rumah sakit. Ruang lingkup kesehatan lingkungan sesuai Permenkes bahwa penyehatan ruang bangunan dan halaman rumah sakit, pengamanan dampak radiasi dan juga pengelolaan limbah. Karena pengaruh limbah rumah sakit terhadap kualitas lingkungan dan kesehatan dapat menimbulkan berbagai macam masalah.

Green hospital merupakan satu hasil implementasi konsep green building atau dikenal juga sebagai sustainable building, dimana memperhatikan aspek-aspek lingkungan, mulai dari perancangan, pembangunan, pengoperasian, hingga pemeliharaan. Tujuan dari green building tersebut adalah optimalisasi sumber daya dalam jumlah yang sedikit, sehingga mengurangi dampak lingkungan.Hal ini lah yang membuat penulis tertarik untuk melakukan penelitian tentang evaluasi implementasi kebijakan manajemen limbah padat medis dan non medis rumah sakit menuju green hospital. Penelitian (Setyawati, 2018) mengatakan bahwa kinerja lingkungan Rumah Sakit akan baik apabila Unit Pengelola Lingkungan di 
Rumah Sakit mempunyai SDM lingkungan yang cukup, ketersediaan anggaran dan mempunyai sarana dan teknologi lingkungan yang memadai Peraturan di bidang lingkungan ditaati dengan menerapkan standar mutu. Hasil penelitian (Putri, Purnomo, \& Astuti, 2016) mengatakan Rumah sakit di Kota Malang saat ini secara rata-rata menunjukkan tingkat kesiapan yang sedang. Pada kriteria Pengelolaan Sumberdaya sebagai kriteria dengan kesiapan terendah, disebabkan oleh sub kriteria Pengelolaan Transportasi dan Pengelolaan Makanan Sedangkan pada kriteria Bangunan, perlu peningkatan kesiapan yang terkait dengan sub kriteria Bahan Bangunan. Pada kriteria PROPER (komitmen manajemen pada pengelolaan limbah), perlu peningkatan kesiapan terutama pada sub kriteria Pengelolaan Limbah Udara dan Pengelolaan Limbah B3 Menjadi green hospital merupakan sebuah pilihan bijak dan elegan pada era persaingan bebas. Sebuah rumah sakit dapat merevisi visi dan misi perusahaan untuk merintis menjadi green hospital di masa mendatang.

Berdasarkan latarbelakang masalah yang telah diuraikan diatas, maka peneliti akan mengkaji secara teoritik rumah sakit dalam rangka green hospital di kota bali dengan kriteria green hospital healty and care.
DOI : doi.org/10.21009/jgg.082.03

\section{METODOLOGI}

Penelitian ini menggunakan teknik pengumpulan data dengan instrurmen. Instrumen penelitian berupa kuesioner dalam memperoleh data yang diperlukan. Istrumen penelitian adalah alat yang digunakan oleh penelitian dalam mengumpulkan data agar memudahkan mengumpulkan, mengolah, menyajikan data yang bermanfaat dalam menjawab masalah penelitian. Sampel dalam penelitian ini sebanyak 30 responden. Data yang diperoleh melalui kuesioner disajikan dengan menggunakan analisis secara deskriptif untuk dibuat kesimpulan. Teknik sampling yang digunakan untuk penentuan sampel adalah random sampling yaitu pengambilan sampel secara acak. Teknik pengambilan data menggunakan satu variable yang akan dikaji, yaitu Green Hospital. Setiap instrumen penelitian berpedoman pada konsepsional yang meliputi definisi konseptual, definisi operasional, kisi-kisi instrumen penelitian.

Data akan diolah dengan menggunakan statistik sederhana dengan rumus persentase $(\mathbf{P})$ yaitu :

\section{$\mathbf{F}$}

Persentasi $(P)=-x 100 \%$

$\mathbf{N}$

Ket :

F : Frekuensi Jawaban dari Responden

N : Jumlah Responden Seluruhnya 


\section{Hasil dan Pembahasan}

Berdasarkan hasil penelitian tersebut diperoleh gambaran tentang rumah sakit yang menuju green hospital sebagai berikut

1. Apakah anda pernah menemukan rumah yang memprioritaskan rumah sakit yang ramah lingkungan?

Tabel 1. Kepemimpinan

\begin{tabular}{|c|l|c|c|}
\hline No & \multicolumn{1}{|c|}{$\begin{array}{c}\text { Alternatif } \\
\text { Jawaban }\end{array}$} & Frekuensi & Persentase \\
\hline 1 & Selalu & 3 & $10 \% \%$ \\
\hline 2 & Sering & 5 & $16,7 \%$ \\
\hline 3 & Kadang-kadang & 14 & $46,7 \%$ \\
\hline 4 & Jarang & 5 & $16,7 \%$ \\
\hline 5 & Tidak Pernah & 3 & $10 \%$ \\
\hline & Jumlah & 30 & $100 \%$ \\
\hline
\end{tabular}

Data dari tabel tersebut menunjukkan bahwa sebanyak 3 responden (10\%) menjawab selalu, 5 responden $(16,7 \%)$ menjawab sering, 14 responden $(46,7 \%)$ kadang-kadang, 5 responden $(16,7 \%)$ menjawab jarang, dan 3 responden (10\%) menjawab tidak pernah.

Dari data tersebut dapat disimpulkan bahwa sebagian besar masyarakat menyatakan “ kadang-kadang" menemukan rumah sakit yang ramah lingkungan.

2. Apakah anda pernah menemukan rumah sakit yang menyajikan makanan junkfood?

Tabel 2. Makanan Lokal

\begin{tabular}{|l|c|c|c|}
\hline No & Alternatif & Frekuensi & Persentase \\
\hline
\end{tabular}

\begin{tabular}{|c|c|c|c|}
\hline & Jawaban & & \\
\hline 1 & Selalu & 1 & $3.3 \%$ \\
\hline 2 & Sering & 1 & $3,3 \%$ \\
\hline 3 & Kadang-kadang & 1 & $3,3 \%$ \\
\hline 4 & Jarang & 2 & $6,7 \%$ \\
\hline \multirow[t]{2}{*}{5} & Tidak Pernah & 28 & 93,3 \\
\hline & Jumlah & 30 & $100 \%$ \\
\hline
\end{tabular}

Data dari tabel tersebut menunjukkan bahwa sebanyak 1 responden $(3,3 \%)$ menjawab selalu, 1 responden $(3,3 \%)$ menjawab sering, 1 responden $(3,3 \%)$ kadang-kadang, 2 responden $(6,7 \%)$ menjawab jarang, dan 28 responden $(93,3 \%)$ menjawab tidak pernah.

Dari data tersebut dapat disimpulkan bahwa sebagian besar masyarakat menyatakan " tidak pernah" menemukan yang menyajikan makanan junkfood.

3. Apakah anda pernah menemukan rumah sakit yang mengelola limbah dengan baik dan benar?

\section{Tabel 3. Pengelolaan Limbah}

\begin{tabular}{|c|l|c|c|}
\hline No & $\begin{array}{c}\text { Alternatif } \\
\text { Jawaban }\end{array}$ & Frekuensi & Persentase \\
\hline 1 & Selalu & 9 & $30 \%$ \\
\hline 2 & Sering & 8 & $26,7 \%$ \\
\hline 3 & Kadang-kadang & 6 & $20 \%$ \\
\hline 4 & Jarang & 4 & $13,3 \%$ \\
\hline 5 & Tidak Pernah & 3 & $3,3 \%$ \\
\hline & Jumlah & 30 & $100 \%$ \\
\hline
\end{tabular}

Data dari tabel tersebut menunjukkan bahwa sebanyak 9 responden $(30 \%)$ menjawab selalu, 8 responden $(26,7 \%)$ 
menjawab sering, 6 responden $(20 \%)$ kadang-kadang, 4 responden $(13,3 \%)$ menjawab jarang, dan 3 responden $(3,3 \% \%)$ menjawab tidak pernah.

Dari data tersebut dapat disimpulkan bahwa sebagian besar masyarakat menyatakan " selalu" menemukan sakit yang mengelola limbah dengan baik dan benar.

4. Apakah anda pernah menemukan rumah sakit yang menggunakan bahan bangunan yang tidak ramah akan lingkungan?

Tabel 4. Penggunaan Air

\begin{tabular}{|c|l|c|c|}
\hline No & \multicolumn{1}{|c|}{$\begin{array}{c}\text { Alternatif } \\
\text { Jawaban }\end{array}$} & Frekuensi & Persentase \\
\hline 1 & Selalu & 2 & $6,7 \%$ \\
\hline 2 & Sering & 8 & $26,7 \%$ \\
\hline 3 & Kadang-kadang & 9 & $30 \%$ \\
\hline 4 & Jarang & 4 & $13,3 \%$ \\
\hline 5 & Tidak Pernah & 5 & $16,7 \%$ \\
\hline & Jumlah & 30 & $100 \%$ \\
\hline
\end{tabular}

Data dari tabel tersebut menunjukkan bahwa sebanyak 2 responden $(6,7 \%)$ menjawab selalu, 8 responden $(26,7)$ menjawab sering, 9 responden $(33,3 \%)$ kadang-kadang, 4 responden $(13,3 \%)$ menjawab jarang, dan 5 responden $(16,7 \%)$ menjawab tidak pernah.

Dari data tersebut dapat disimpulkan bahwa sebagian besar masyarakat menyatakan “ kadang-kadang” menemukan rumah sakit yang menggunakan bahan bangunan yang tidak ramah akan lingkungan.

5. Apakah anda pernah menemukan rumah sakit yang sulit untuk mengeluarkan perizinan dalam menggunakan transportasi rumah sakit?

\section{Tabel 5. Transportasi}

\begin{tabular}{|c|l|c|c|}
\hline No & \multicolumn{1}{|c|}{$\begin{array}{c}\text { Alternatif } \\
\text { Jawaban }\end{array}$} & Frekuensi & Persentase \\
\hline 1 & Selalu & 3 & $10 \%$ \\
\hline 2 & Sering & 6 & $20 \%$ \\
\hline 3 & Kadang-kadang & 8 & $26,7 \%$ \\
\hline 4 & Jarang & 6 & $20 \%$ \\
\hline 5 & Tidak Pernah & 7 & $23,3 \%$ \\
\hline & Jumlah & 30 & $100 \%$ \\
\hline
\end{tabular}

Data dari tabel tersebut menunjukkan bahwa sebanyak 3 responden (10\%) menjawab selalu, 6 responden (20\%) menjawab sering, 8 responden $(26,7 \%)$ kadang-kadang, $\quad 6$ responden $(20 \%)$ menjawab jarang, dan 7 responden $(16,7 \%)$ menjawab tidak pernah.

Dari data tersebut dapat disimpulkan bahwa sebagian besar masyarakat menyatakan " kadang-kadang" rumah sakit yang sulit untuk mengeluarkan perizinan dalam menggunakan transportasi rumah sakit.

6. Apakah anda pernah menemukan rumah sakit yang mengefisiensikan penggunaan air?

Tabel 6. Penggunaan Air

\begin{tabular}{|c|c|c|c|}
\hline No & $\begin{array}{c}\text { Alternatif } \\
\text { Jawaban }\end{array}$ & Frekuensi & Persentase \\
\hline 1 & Selalu & 10 & $33,3 \%$ \\
\hline
\end{tabular}




\begin{tabular}{|c|l|c|c|}
\hline 2 & Sering & 7 & $23,3 \%$ \\
\hline 3 & Kadang-kadang & 8 & $26,7 \%$ \\
\hline 4 & Jarang & 3 & $16,7 \%$ \\
\hline 5 & Tidak Pernah & 2 & $6,7 \%$ \\
\hline & Jumlah & 30 & $100 \%$ \\
\hline
\end{tabular}

menjawab jarang, dan 8 responden $(26,7 \%)$ menjawab tidak pernah.

Dari data tersebut dapat disimpulkan bahwa sebagian besar masyarakat menyatakan "jarang" rumah sakit yang meminimalisir penggunaan bahan-bahan kimia.

menjawab selalu, 7 responden $(23,3 \%)$ menjawab sering, 8 responden $(26,7 \%)$ kadang-kadang, 3 responden $(16,7 \%)$ menjawab jarang, dan 2 responden $(6,7 \%)$ menjawab tidak pernah.

Dari data tersebut dapat disimpulkan bahwa sebagian besar masyarakat menyatakan "selalu" rumah sakit yang mengefisiensikan penggunaan air.

Tabel 8. Pengelolaan Limbah

7. Apakah anda pernah menemukan rumah sakit yang meminimalisir penggunaan bahan-bahan kimia?

Tabel 7. Penggunaan Bahan Kimia

\begin{tabular}{|c|l|c|c|}
\hline No & \multicolumn{1}{|c|}{$\begin{array}{c}\text { Alternatif } \\
\text { Jawaban }\end{array}$} & Frekuensi & Persentase \\
\hline 1 & Selalu & 3 & $10 \%$ \\
\hline 2 & Sering & 2 & $6,7 \%$ \\
\hline 3 & Kadang-kadang & 6 & $20 \%$ \\
\hline 4 & Jarang & 11 & $36,7 \%$ \\
\hline 5 & Tidak Pernah & 8 & $26,7 \%$ \\
\hline & \multicolumn{1}{|c|}{ Jumlah } & 30 & $100 \%$ \\
\hline
\end{tabular}

Data dari tabel tersebut menunjukkan bahwa sebanyak 3 responden (10\%) menjawab selalu, 2 responden $(6,7 \%)$ menjawab sering, 6 responden (20\%) kadang-kadang, 11 responden $(36,7 \%)$ 8. Apakah anda pernah menemukan rumah sakit yang mendaur ulang kembali limbah/sampah yang dihasilkan dari rumah sakit tersebut?

\begin{tabular}{|c|l|c|c|}
\hline No & $\begin{array}{c}\text { Alternatif } \\
\text { Jawaban }\end{array}$ & Frekuensi & Persentase \\
\hline 1 & Selalu & 8 & $26,7 \%$ \\
\hline 2 & Sering & 9 & $30 \%$ \\
\hline 3 & Kadang-kadang & 6 & $20 \%$ \\
\hline 4 & Jarang & 4 & $13,3 \%$ \\
\hline 5 & Tidak Pernah & 3 & $16,7 \%$ \\
\hline & Jumlah & 30 & $100 \%$ \\
\hline
\end{tabular}

Data dari tabel tersebut menunjukkan bahwa sebanyak 8 responden $(26,7 \%)$ menjawab selalu, 9 responden $(30 \%)$ menjawab sering, 6 responden (20\%) kadang-kadang, 4 responden $(13,3 \%)$ menjawab jarang, dan 3 responden $(16,7 \%)$ menjawab tidak pernah.

Dari data tersebut dapat disimpulkan bahwa sebagian besar 
masyarakat menyatakan “ sering” rumah sakit yang mendaur ulang kembali limbah/sampah yang dihasilkan dari rumah sakit tersebut.

9. Apakah anda pernah menemukan rumah sakit yang memiliki ruang terbuka yang hijau?

Tabel 9. Pengadaan Bangunan

\begin{tabular}{|c|l|c|c|}
\hline No & $\begin{array}{c}\text { Alternatif } \\
\text { Jawaban }\end{array}$ & Frekuensi & Persentase \\
\hline 1 & Selalu & 5 & $16,7 \%$ \\
\hline 2 & Sering & 5 & $16,7 \%$ \\
\hline 3 & Kadang-kadang & 6 & $20 \%$ \\
\hline 4 & Jarang & 11 & $36,7 \%$ \\
\hline 5 & Tidak Pernah & 3 & $13,3 \%$ \\
\hline & Jumlah & 30 & $100 \%$ \\
\hline
\end{tabular}

Data dari tabel tersebut menunjukkan bahwa sebanyak 5 responden $(16,7 \%)$ menjawab selalu, 5 responden $(16,7 \%)$ menjawab sering, 11 responden $(36,7 \%)$ kadang-kadang, 5 responden $(16,7 \%)$ menjawab jarang, dan 3 responden $(13,3 \%)$ menjawab tidak pernah.

Dari data tersebut dapat disimpulkan bahwa sebagian besar masyarakat menyatakan "jarang" menemukan rumah sakit yang ramah lingkungan.

10. Apakah anda pernah menemukan rumah sakit yang pengelolaan limbahnya tidak dengan benar?

Tabel 10. Pengelolaan Limbah

\begin{tabular}{|l|c|c|c|}
\hline No & Alternatif & Frekuensi & Persentase \\
\hline
\end{tabular}

\begin{tabular}{|c|l|c|c|}
\hline & \multicolumn{1}{|c|}{ Jawaban } & & \\
\hline 1 & Selalu & 4 & $13,3 \%$ \\
\hline 2 & Sering & 4 & $13,3 \%$ \\
\hline 3 & Kadang-kadang & 8 & $26,7 \%$ \\
\hline 4 & Jarang & 5 & $16,7 \%$ \\
\hline 5 & Tidak Pernah & 3 & $10 \%$ \\
\hline & Jumlah & 30 & $100 \%$ \\
\hline
\end{tabular}

Data dari tabel tersebut menunjukkan bahwa sebanyak 4 responden $(13,3 \%)$ menjawab selalu, 4 responden $(13,3 \%)$ menjawab sering, 8 responden $(26,7 \%)$ kadang-kadang, 5 responden $(16,7 \%)$ menjawab jarang, dan 3 responden (10\%) menjawab tidak pernah.

Dari data tersebut dapat disimpulkan bahwa sebagian besar masyarakat menyatakan "kadang-kadang" menemukan rumah sakit yang pengelolaan limbahnya tidak dengan benar.

11. Apakah anda pernah menemukan rumah sakit yang menyediakan obat-obat dari bahan alami?

Tabel 11. Pengelolaan Farmasi

\begin{tabular}{|c|l|c|c|}
\hline No & $\begin{array}{c}\text { Alternatif } \\
\text { Jawaban }\end{array}$ & Frekuensi & Persentase \\
\hline 1 & Selalu & 1 & $3,3 \%$ \\
\hline 2 & Sering & 2 & $6,7 \%$ \\
\hline 3 & Kadang-kadang & 3 & $10 \%$ \\
\hline 4 & Jarang & 3 & $10 \%$ \\
\hline 5 & Tidak Pernah & 21 & $70 \%$ \\
\hline & Jumlah & 30 & $100 \%$ \\
\hline
\end{tabular}

Data dari tabel tersebut menunjukkan bahwa sebanyak 1 responden $(3,3 \%)$ 
menjawab selalu, 2 responden $(6,7)$ menjawab sering, 3 responden $(10 \%)$ kadang-kadang, 3 responden $\quad(10 \%)$ menjawab jarang, dan 21 responden $(70 \%)$ menjawab tidak pernah.

Dari data tersebut dapat disimpulkan bahwa sebagian besar masyarakat menyatakan "tidak pernah" rumah sakit yang menyediakan obat-obat dari bahan alami.

12. Apakah anda pernah menemukan rumah sakit yang memiliki pemimpin peduli terhadap lingkungan?

Tabel 12. Pemimpin

\begin{tabular}{|c|l|c|c|}
\hline No & $\begin{array}{c}\text { Alternatif } \\
\text { Jawaban }\end{array}$ & Frekuensi & Persentase \\
\hline 1 & Selalu & 10 & $33,3 \%$ \\
\hline 2 & Sering & 7 & $23,3 \%$ \\
\hline 3 & Kadang-kadang & 5 & $16,7 \%$ \\
\hline 4 & Jarang & 4 & $13,3 \%$ \\
\hline 5 & Tidak Pernah & 4 & $13,3 \%$ \\
\hline & Jumlah & 30 & $100 \%$ \\
\hline
\end{tabular}

Data dari tabel tersebut menunjukkan bahwa sebanyak 10 responden $(33,3 \%)$ menjawab selalu, 7 responden $(2,3 \%)$ menjawab sering, 5 responden $(16,7 \%)$ kadang-kadang, 4 responden $(13,3 \%)$ menjawab jarang, dan 4 responden $(13,3 \%)$ menjawab tidak pernah.

Dari data tersebut dapat disimpulkan bahwa sebagian besar masyarakat menyatakan "selalu" rumah sakit yang memiliki pemimpin peduli terhadap lingkungan.
13. Apakah anda pernah menemukan rumah sakit yang boros dalam menggunakan energi listrik?

Tabel 13. Penggunaan Energi

\begin{tabular}{|c|l|c|c|}
\hline No & \multicolumn{1}{|c|}{$\begin{array}{c}\text { Alternatif } \\
\text { Jawaban }\end{array}$} & Frekuensi & Persentase \\
\hline 1 & Selalu & 5 & $16,7 \%$ \\
\hline 2 & Sering & 6 & $20 \%$ \\
\hline 3 & Kadang-kadang & 11 & $36,7 \%$ \\
\hline 4 & Jarang & 6 & $20 \%$ \\
\hline 5 & Tidak Pernah & 2 & $6,7 \%$ \\
\hline & \multicolumn{1}{|c|}{ Jumlah } & 30 & $100 \%$ \\
\hline
\end{tabular}

Data dari tabel tersebut menunjukkan bahwa sebanyak 5 responden $(16,7 \%)$ menjawab selalu, 6 responden (20\%) menjawab sering, 11 responden $(36,7 \%)$ kadang-kadang, 6 responden $(20 \%)$ menjawab jarang, dan 2 responden $(6,7 \%)$ menjawab tidak pernah.

Dari data tersebut dapat disimpulkan bahwa sebagian besar masyarakat menyatakan " kadang-kadang” rumah sakit yang boros dalam menggunakan energi listrik.

14. Apakah anda pernah menemukan rumah sakit yang memberitahukan himbauan untuk hemat menggunakan air?

Tabel 14. Pengelolaan Air

\begin{tabular}{|c|l|c|c|}
\hline No & $\begin{array}{c}|c| \\
\text { Alternatif } \\
\text { Jawaban }\end{array}$ & Frekuensi & Persentase \\
\hline 1 & Selalu & 22 & $73,3 \%$ \\
\hline 2 & Sering & 3 & $10 \%$ \\
\hline 3 & Kadang-kadang & 2 & $6,7 \%$ \\
\hline 4 & Jarang & 2 & $6,7 \%$ \\
\hline
\end{tabular}




\begin{tabular}{|c|c|c|c|}
\hline 5 & Tidak Pernah & 1 & $3,3 \%$ \\
\hline & Jumlah & 30 & $100 \%$ \\
\hline
\end{tabular}

Data dari tabel tersebut menunjukkan bahwa sebanyak 22 responden $(73,3 \%)$ menjawab selalu,3 responden (10\%) menjawab sering, 2 responden $(6,7 \%)$ kadang-kadang, 2 responden $\quad(6,7 \%)$ menjawab jarang, dan 1 responden $(3,3 \%)$ menjawab tidak pernah.

Dari data tersebut dapat disimpulkan bahwa sebagian besar masyarakat menyatakan "selalu" menemukan rumah sakit yang memberitahukan himbauan untuk hemat menggunakan air.

15. Apakah anda pernah menemukan pemimpin rumah sakit mementingkan pelayanan penyembuhan penyakit daripada kelestarian lingkungan?

Tabel 15. Kepemimpinan

\begin{tabular}{|c|l|c|c|}
\hline No & $\begin{array}{c}\text { Alternatif } \\
\text { Jawaban }\end{array}$ & Frekuensi & Persentase \\
\hline 1 & Selalu & 14 & $46,7 \%$ \\
\hline 2 & Sering & 6 & $20 \%$ \\
\hline 3 & Kadang-kadang & 5 & $16,7 \%$ \\
\hline 4 & Jarang & 3 & $10 \%$ \\
\hline 5 & Tidak Pernah & 2 & $6,7 \%$ \\
\hline & Jumlah & 30 & $100 \%$ \\
\hline
\end{tabular}

Data dari tabel tersebut menunjukkan bahwa sebanyak 14 responden $(46,7 \%)$ menjawab selalu, 6 responden (20\%) menjawab sering, 5 responden $(16,7 \%)$ kadang-kadang, 3 responden $\quad(10 \%)$ menjawab jarang, dan 2 responden $(6,7 \%)$
DOI : doi.org/10.21009/jgg.082.03

menjawab tidak pernah.

Dari data tersebut dapat disimpulkan bahwa sebagian besar masyarakat menyatakan " selalu" pemimpin rumah sakit mementingkan pelayanan penyembuhan penyakit daripada kelestarian lingkungan.

16. Apakah anda pernah menemukan rumah sakit yang memiliki konsep desain bangunan yang ramah lingkungan?

Tabel 16. Pengelolaan Bangunan

\begin{tabular}{|c|c|c|c|}
\hline No & $\begin{array}{c}\text { Alternatif } \\
\text { Jawaban }\end{array}$ & Frekuensi & Persentase \\
\hline 1 & Selalu & 4 & $13,3 \%$ \\
\hline 2 & Sering & 7 & $23,3 \%$ \\
\hline 3 & Kadang-kadang & 10 & $33,3 \%$ \\
\hline 4 & Jarang & 5 & $16,7 \%$ \\
\hline 5 & Tidak Pernah & 4 & $13,3 \%$ \\
\hline & Jumlah & 30 & $100 \%$ \\
\hline
\end{tabular}

Data dari tabel tersebut menunjukkan bahwa sebanyak 4 responden $(13,3 \%)$ menjawab selalu, 7 responden $(23,3 \%)$ menjawab sering, 10 responden $(33,3 \%)$ kadang-kadang, 5 responden $(16,7 \%)$ menjawab jarang, dan 4 responden $(13,3 \%)$ menjawab tidak pernah.

Dari data tersebut dapat disimpulkan bahwa sebagian besar masyarakat menyatakan " kadang-kadang" rumah sakit yang memiliki konsep desain bangunan yang ramah lingkungan.

17. Apakah anda pernah menemukan 
rumah sakit yang menggunakan bahan

bangunan yang ramah akan lingkungan?

Tabel 17. Pengadaan Barang

\begin{tabular}{|c|l|c|c|}
\hline No & \multicolumn{1}{|c|}{$\begin{array}{c}\text { Alternatif } \\
\text { Jawaban }\end{array}$} & Frekuensi & Persentase \\
\hline 1 & Selalu & 2 & $6,7 \%$ \\
\hline 2 & Sering & 5 & $16,7 \%$ \\
\hline 3 & Kadang-kadang & 6 & $20 \%$ \\
\hline 4 & Jarang & 9 & $30 \%$ \\
\hline 5 & Tidak Pernah & 8 & $26,7 \%$ \\
\hline & Jumlah & 30 & $100 \%$ \\
\hline
\end{tabular}

Data dari tabel tersebut menunjukkan bahwa sebanyak 2 responden $(6,7 \%)$ menjawab selalu, 5 responden $(16,7 \%)$ menjawab sering, 6 responden $(20 \%)$ kadang-kadang, 9 responden $(30 \%)$ menjawab jarang, dan 8 responden $(26,7 \%)$ menjawab tidak pernah.

Dari data tersebut dapat disimpulkan bahwa sebagian besar masyarakat menyatakan "jarang" menemukan rumah sakit yang menggunakan bahan bangunan yang ramah akan lingkungan.

18. Apakah anda pernah menemukan rumah sakit yang menggunakan teknologiteknologi terbaru yang ramah lingkungan?

Tabel 18. Pengadaan Barang

\begin{tabular}{|c|l|c|c|}
\hline No & \multicolumn{1}{|c|}{$\begin{array}{c}\text { Alternatif } \\
\text { Jawaban }\end{array}$} & Frekuensi & Persentase \\
\hline 1 & Selalu & 10 & $33,3 \%$ \\
\hline 2 & Sering & 7 & $23,3 \%$ \\
\hline 3 & Kadang-kadang & 6 & $20 \%$ \\
\hline 4 & Jarang & 6 & $20 \%$ \\
\hline 5 & Tidak Pernah & 1 & $3,3 \%$ \\
\hline
\end{tabular}

DOI : doi.org/10.21009/jgg.082.03

\begin{tabular}{|l|c|c|c|}
\hline & Jumlah & 30 & $100 \%$ \\
\hline
\end{tabular}

Data dari tabel tersebut menunjukkan bahwa sebanyak 10 responden $(33,3 \%)$ menjawab selalu, 7 responden $(233 \%)$ menjawab sering, 6 responden (20\%) kadang-kadang, 6 responden $(20 \%)$ menjawab jarang, dan 1 responden $(3,3 \%)$ menjawab tidak pernah.

Dari data tersebut dapat disimpulkan bahwa sebagian besar masyarakat menyatakan "selalu" menemukan rumah sakit yang menggunakan teknologi-teknologi terbaru.

19. Apakah anda pernah menemukan rumah sakit yang memberdayakan produk makanan lokal?

Tabel 19. Pengelolaan Makanan

\begin{tabular}{|c|l|c|c|}
\hline No & \multicolumn{1}{|c|}{$\begin{array}{c}\text { Alternatif } \\
\text { Jawaban }\end{array}$} & Frekuensi & Persentase \\
\hline 1 & Selalu & 2 & $6,7 \%$ \\
\hline 2 & Sering & 7 & $23,4 \%$ \\
\hline 3 & Kadang-kadang & 6 & $20 \%$ \\
\hline 4 & Jarang & 9 & $30 \%$ \\
\hline 5 & Tidak Pernah & 6 & $20 \%$ \\
\hline & Jumlah & 30 & $100 \%$ \\
\hline
\end{tabular}

Data dari tabel tersebut menunjukkan bahwa sebanyak 2 responden $(6,7 \%)$ menjawab selalu, 7 responden $(23,3 \%)$ menjawab sering, 6 responden $(20 \%)$ kadang-kadang, $\quad 9$ responden $\quad(30 \%)$ menjawab jarang, dan 6 responden (20\%) menjawab tidak pernah. 
Dari data tersebut dapat disimpulkan bahwa sebagian besar masyarakat menyatakan 'jarang” menemukan rumah sakit yang memberdayakan produk makanan lokal.

20. Apakah anda pernah menemukan rumah sakit yang mengefisiensikan penggunaan energi?

Tabel 20. Penggunaan Energi

\begin{tabular}{|c|c|c|c|}
\hline No & $\begin{array}{c}\text { Alternatif } \\
\text { Jawaban }\end{array}$ & Frekuensi & Persentase \\
\hline 1 & Selalu & 15 & $50 \%$ \\
\hline 2 & Sering & 7 & $23,3 \%$ \\
\hline 3 & Kadang-kadang & 8 & $26,7 \%$ \\
\hline 4 & Jarang & 2 & $6,7 \%$ \\
\hline 5 & Tidak Pernah & 3 & $10 \%$ \\
\hline & Jumlah & 30 & $100 \%$ \\
\hline
\end{tabular}

Data dari tabel tersebut menunjukkan bahwa sebanyak 15 responden (50\%) menjawab selalu, 7 responden $(23,3 \%)$ menjawab sering, 8 responden $(26,7 \%)$ kadang-kadang, 2 responden $\quad(6,7 \%)$ menjawab jarang, dan 3 responden (10\%) menjawab tidak pernah.

Dari data tersebut dapat disimpulkan bahwa sebagian besar masyarakat menyatakan 'selalu' rumah sakit yang mengefisiensikan penggunaan energi.

Berdasarkan deskripsi data penelitian yang telah diuraikan di atas dapat dilakukan analisis sebagai berikut :
1. Kepemimpinan

Data penelitian yang berkaitan dengan bentuk kepemimpinan pengelolaan lingkungan rumah sakit $46,7 \%$ menyatakan menemukan pemimpin rumah sakit yang mengutamakan memprioritaskan rumah sakit yang ramah lingkungan.

\section{Penggunaan Energi}

Data penelitian yang berkaitan dengan bentuk penggunaan energi dirumah sakit $50 \%$ mengatakan menemumengefisiensikan penggunaan energi.

\section{Penggunaan Air}

Data penelitian yang berkaitan dengan bentuk himbauan dan penggunaan air dir umah sakit sekitar 70\% menyatakan menemukan rumah sakit yang mengefisiensikan air, termasuk dalam memberikan himbauan agar menggunakan air dengan efisien.

\section{Penggunaan Bahan Kimia}

Data penelitian yang berkaitan dengan bentuk pengunaan bahan kimia di rumah sakit sekitar $36,7 \%$ menyatakan rumah sakit meminimalisir penggunaan bahanbahan kimia

5. Pengelolaan Limbah 
Data penelitian yang berkaitan dengan bentuk pengelolaan limbah lingkungan rumah sakit sekitar $70 \%$ menyatakan menemukan rumah sakit yang mengefisiensikan air, termasuk dalam memberikan himbauan dalam pemakaian air dirumah sakit.

6. Bangunan

Data penelitian yang berkaitan dengan bentuk konsep bangunan rumah sakit sekitar 33,3\% menyatakan memiliki ruang terbuka hijau di rumah sakit.

7. Penyediaan Makanan

Data penelitian yang berkaitan dengan bentuk penyediaan makanan sekitar $30 \%$ menyatakan jarang menemukan makanan produk lokal.

8. Penggunaan Farmasi

Data penelitian yang berkaitan dengan bentuk penggunaan farmasi sekitar $70 \%$ mengatakan masih menggunakan obat-obat dari bahan kimia.

9. Pengadaan Barang

Data penelitian yang berkaitan dengan bentuk pengadaan barang sekitar 33,3\% menyatakan menemukan rumah sakit yang menggunakan teknolgi-teknologi yang ramah lingkungan.

\section{KESIMPULAN}

Jumlah rumah sakit yang semakin bertambah banyak berpengaruh terhadap kerusakan lingkungan apabil tidak dikelola dengan baik. Kerusakan lingkungan menjadi tanggungjawab bersama-sama baik dari pihak pemerintah, swasta dan masyarakat. Di indonesia saat ini bahkan belum ada rumah sakit yang sudah termasuk green hospital, namun pemerintah mempersiapkan pada tahun 2020 setiap rumah sakit diharapkan dapat berpartisipasi dalam mengelola secara baik dengan selalu mempertimbangkan aspek kesehatan, ekonomi, ekologi dan sosial sehingga prinsip pemenuhan konsep pembangunan berkelanjutan dalam bidang kesehatan akan terpenuhi, dan rumah sakit dapat ikut berperan aktif dalam meminimalisasi dampak perubahan iklim. Dari hasil penelitian ini menyatakan bahwa dari 10 kategori green hopsital dunia rumah sakit di Bali masih harus banyak yang di persiapkan.

\section{DAFTAR PUSTAKA}

A.A. Gde Muninjaya 2015 Manajemen Kesehatan. Jakarta: Penerbit Buku. Kedokteran EGC

Alhumoud, JM; Alhumoud, HM (2007). An analysis of trends related to hospital solid wastes management in Kuwait. Management of environmental quality international journal. 18 (5): 502 - 513

A. Pruss, dkk. Pengelolaan Aman Limbah Layanan Kesehatan. Jakarta: EGC, 2005. 
Balifokus. (2010). Activity Report. PERFORMANCE, 7(1), 70-90.

Assesment of Environmental Conditions and Inventory for Guidance and TechnicalSupport to Develop Sound Management. Practices for Hospital Wastes. February 2010

Chartier, Y., Emmanuel, J., Pieper, U., Rushbrook, P., Stringer, R., Townend, W., ... Zghondi, R. (2014). Prüss, A., Safe management of wastes from health-care activities. World Health Organization Geneva Switzerland.

Dewi Resti Permata, Sarwono, H. R. (2012). AUDIT DAN KONSERVASI ENERGI PADA RUMAH SAKIT ANGKATAN LAUT dr. RAMELAN SURABAYA, 1-8.

Fahriza Risnawati, P.Purwanto, O. S. (2015). Penerapan Green Hospital sebagai Upaya Manajemen Lingkungan Di Rumah Sakit Pertamina Cirebon, VII(1).

Hartati, R. S., Magister, P., Elektro, T., Teknik, F., Udayana, U., Mineral, D., \& Elektro, T. (2012). Manajemen energi di rumah sakit surya husadha denpasar, 11(2).

Peraturan Menteri Kesehatan 2004

Putri, C. F., Purnomo, D., \& Astuti, E. (2016). Analisis Kesiapan Rumah Sakit Menuju Ramah Lingkungan ( Green Hospital ) di Kota Malang, 1217.

Putri, R. E. (2009). Analisis potensi minimisasi limbah padat domestik di Instalasi Gizi dan Tata Boga Rumah Sakit Kanker "Dharmais," 1-5.

Robbins, Stephen P. dan Mary Coulter. (2005). Management. 8th Edition. Prentice Hall, New Jersey

Setyawati, S. (2018). HOSPITAL ENVIRONMENTAL
Undang-undang 1945

World Health Organization International

Yahar. (2011). Studi Tentang Pengelolaan Limbah Medis di Rumah sakit Umum Daerah Kab.Barru, 1-97. 